\title{
SOME HORMONAL ASPECTS OF WATER EXCRETION IN MAN ${ }^{1}$
}

\author{
By ALEXANDER LEAF,2 AUDLEY R. MAMBY,3 HOWARD RASMUSSEN, AND \\ JOAN P. MARASCO
}

\author{
(From the Departments of Medicine of the Massachusetts General Hospital and the Harvard \\ Medical School, Boston, Mass.)
}

(Submitted for publication February 23, 1952; accepted August 1, 1952)

In 1918 von Hann (1) suggested, as a result of her post mortem studies in man, that destruction of the posterior pituitary caused diabetes insipidus only if significant portions of the anterior pituitary gland remained intact. This observation has been supported by other workers who noted that in experimental diabetes insipidus, destruction of the anterior pituitary resulted in decrease in the polyuria and polydipsia (2-7).

In 1935 Mahoney and Sheehan (8) showed that experimental diabetes insipidus in the dog can be ameliorated by thyroidectomy and the polyuria can be reestablished by thyroid feeding. Fisher, Ingram and Ranson (9) confirmed this result in experimental diabetes insipidus as have others $(6$, 7, 10-14). Similar relationships for adrenal cortical activity to the diabetes insipidus state have been claimed $(15,16)$ and much has been said regarding the diuretic action of adrenal hormones $(16,17)$. It should be stressed that all this work was done on animals in which the degree of polyuria and polydipsia was the sole criterion of the diabetes insipidus state.

This study was done on a patient who had, in addition to well documented neurohypophyseal insufficiency, evidence of some concomitant anterior pituitary failure. The purpose of this paper is to reemphasize the physiological defect in diabetes insipidus; and to study its relationship to solute loading, thyroid, adrenal, and anterior pituitary function. The findings clearly show that polyuria and polydipsia are not necessary accompaniments of insufficiency of the supraopticohypophyseal system and suggest that the anterior pituitary,

\footnotetext{
1 Supported in part by a Grant-in-Aid from the American Heart Association.

2 National Research Council Fellow in Medical Science 1949-1951, currently Howard R. Hughes Fellow in Medicine.

3 National Institutes of Health Post-Doctorate Research Fellow in Medicine.
}

adrenals, and thyroid do not produce hormones which possess direct diuretic actions.

\section{METHODS}

Balance studies were conducted on the Metabolism Ward of the Massachusetts General Hospital (18). Urine collections were made in 24-hour periods. All bloods were drawn in the fasting state before breakfast except the second sample taken during each dehydration period, which was taken just prior to lunch.

Serum sodium concentrations were done in duplicate by the method of Butler and Tuthill (19). Serum and urine total solute concentrations were determined by the freezing point method utilizing an electrical resistance thermometer apparatus described by Crawford and his associates (20). The apparatus was standardized with sodium chloride solutions of known concentration. The assumption was made, for convenience of expression, that the sodium chloride was totally dissociated and the results were expressed as milliosmols per liter. More correctly, total solute concentration should be expressed as the concentration in millimols of sodium chloride which produces an equivalent depression of the freezing point. This expression is simply obtained by dividing the reported concentration in milliosmols by 2 . All sera were measured without dilution while urines were diluted, only when necessary, into the range of 100 to $300 \mathrm{mOsm}$. per liter. This dilution of the urine, by changing the activity coefficients of certain solutes, introduces a slight error which does not affect our interpretations.

Serum and urine potassium and urine sodium were measured with an internal standard flame photometer (21). Serum and urine chlorides were done by the method of Wilson and Ball (22) ; serum carbon dioxide content, by the method of Van Slyke and Neill (23); serum and urine non-protein nitrogen, by the method of Folin (24); basal metabolic rate, by the closed circuit method of Benedict and Roth (25); renal clearances according to the procedures outlined by Goldring and Chasis (26).

\section{CASE HISTORY}

Mrs. A. J. (M.G.H. 606322) was a 26-year old white woman first seen by Dr. Fuller Albright in January, 1948, at which time she complained of polyuria and polydipsia of two and one half years duration. Symptoms had started during her only pregnancy which terminated in a normal delivery. Urine volumes of 8 liters per day were 
noted. Amenorrhea and weight gain of 20 pounds were present over the past 10 months. Her history was otherwise negative and her physical examination was entirely negative except for very slight obesity.

Laboratory studies revealed persistently dilute urines having specific gravities of 1.003 to 1.005 but showing no other abnormalities. Urine culture was negative. Serum sodium, chloride, cholesterol, calcium, phosphorous, nonprotein nitrogen and blood sugar were normal. The urine follicle-stimulating-hormone assay (27) was weakly positive for 6 mouse units per 24 hours at this time. The hypertonic saline test (28) was positive for neurohypophyseal insufficiency and her urine concentration showed a normal response to pitressin. X-ray examination of the bones revealed a rarified area in the left parietal region measuring 2.2 by $2.5 \mathrm{~cm}$. Biopsy of this area was unsuccessful. A presumptive diagnosis of eosinophilic granuloma as the underlying cause of the diabetes insipidus was made. She completed a first course of $x$-ray therapy to the pituitary region of $1000 \mathrm{r}$ on June 29,1948 . She was placed on a weight reduction diet and given posterior pituitary extract by nasal insufflation for control of the polyuria.

During the remainder of 1948 and most of 1949 she got along well though she had no menses. She reduced her weight to 110 pounds. However, in December, 1949 she was readmitted to the Hospital with the complaints of anorexia, loss of thirst and of polyuria, and marked drowsiness for the preceding six weeks. Examination revealed only a very lethargic patient with a poor memory for recent events who frequently fell asleep during meals or visits. Posterior pituitary extract was withdrawn without recurrence of polyuria or polydipsia. Urine volumes as low as $800 \mathrm{ml}$. in 24 hours were recorded in the Hospital when no posterior pituitary extract was given, volumes certainly not likely to suggest posterior pituitary insufficiency! A second course of $x$-ray therapy of $1000 \gamma$ to the pituitary region was completed in February, 1950.

This spontaneous disappearance of polyuria and polydipsia was reminiscent of the amelioration of experimental diabetes insipidus in animals when the anterior pituitary is destroyed. Hence a survey of the patient's endocrine status was made to evaluate anterior pituitary function with the following results:

1. Amenorrhea with urine Follicle Stimulating Hormone (27) negative for 3 mouse units on April 17, 1950.

2. Loss of axillary and pubic hair in the past few months with urinary $17-$ ketosteroid excretions (29) of $0.0 \mathrm{mgms}$. per 24 hours on February 14, 1950, $0.4 \mathrm{mgm}$. per 24 hours on March 10, 1950 and $1.6 \mathrm{mgm}$. per 24 hours on September 24, 1950.

3. Epinephrine-eosinophile response (30) of -33 per cent on March 27, 1950.

4. Coldness and dryness of the skin and "myxedematous" reflexes (slow relaxation phase) the past year with failure to perspire the past summer. Serum proteinbound iodine (31) was 1.9 gamma per cent on September 25, 1950 and 2.6 gamma per cent on November 2, 1950.
The basal metabolic rate was found to be $-29,-33$ and -30 per cent on November 1, 2, and 3 respectively.

5. The insulin tolerance test (32) on two occasions was found to be essentially normal.

Hence the preponderance of evidence indicates that the patient had partial, but not complete, anterior pituitary failure as well as the previously known deficiency of neurohypophyseal function.

\section{RESULTS}

\section{A. Urine concentration}

The disappearance of polyuria in association with evidence of anterior pituitary failure in this patient with neurohypophyseal insufficiency, brings up the question of what has happened to the renal concentrating ability. Has the polyuria disappeared because of a return of concentrating ability by the kidney when anterior pituitary as well as neurohypophyseal influences are withdrawn?

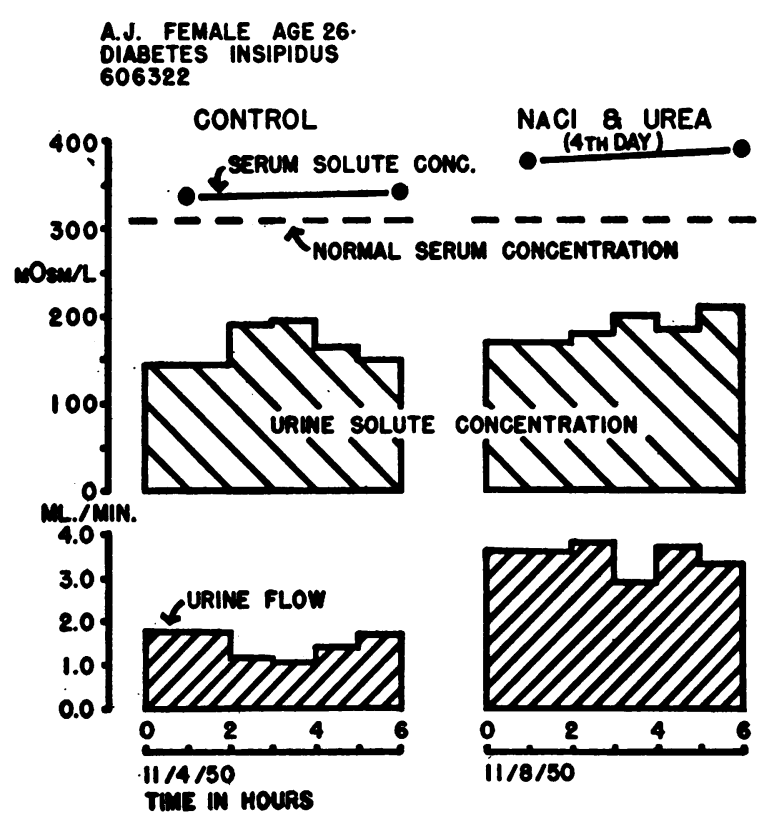

Fig. 1. The Effect on Urine and Serum Total Solute Concentration of Two 14-Hour Periods of Water Deprivation

In spite of marked dehydration, indicated by the high serum total solute concentration, the urine remains very dilute, distinctly hypotonic to the serum. The serum $\mathrm{Na}$ concentration rose to $173 \mathrm{mEq}$./ $\mathrm{L}$. in the second dehydration period. This inability to elaborate a concentrated urine, in spite of an increased effective total solute concentration of the extracellular fluid, is the physiological defect which characterizes neurohypophyseal insufficiency. 
In Figure 1 the results on urine and serum total solute concentrations of two 14 -hour periods of water deprivation are shown. Note that in spite of marked dehydration, which is indicated by the high serum total solute concentrations, the urine remains dilute, distinctly hypotonic to the serum. This is contrary to what is seen in the normal human being during water deprivation when a much smaller increase in serum total solute concentration is associated with a very concentrated urine 1000 to $1200 \mathrm{mOsm}$. per liter (33). This inability to concentrate the urine in the presence of an increased effective osmotic pressure of the serum is the characteristic defect of neurohypophyseal failure (34). Hence this defect was not ameliorated by anterior pituitary insufficiency.

\section{B. Why did the polyuria disappear?}

If the patient still exhibits a failure of renal concentrating ability, the explanation for the disappearance of her previous polyuria must be a low total solute excretion. A large volume of urine was not necessary to excrete a small total solute load even though the urine remained dilute.

While receiving no medications the subject was placed on a diet of her own choosing. Her average 24-hour urine volume was $2844 \mathrm{cc}$. and total solute excretion was 388 mOsm. per 24 hours. This is to be contrasted with the corresponding data from eight normal controls who excreted an average of $866 \mathrm{mOsm}$. per 24 hours. If the subject with her inability to concentrate the urine had chosen a diet that yielded an excretory load equal to the average figure for the controls, she would have required a daily urine volume of some 6500 cc. for its excretion. Such a urine volume would have been compatible with clinically recognizable diabetes insipidus. Thus the disappearance of polyuria in this patient reflected the decreased excretory solute load.

\section{Effects of solute loading}

If this concept that the disappearance of polyuria indicated a reduction in excretory solute load were correct, then giving a solute load should cause return of the polyuria. To test this, the patient was placed on a fixed diet of her own choosing but an ad libitum water intake. After four control days, the subject was given $10 \mathrm{gm}$. of sodium chloride and $15 \mathrm{gm}$. of urea orally daily in six divided dosages for four days (Figure 2). If this were all absorbed it would have added an estimated $595 \mathrm{mOsm}$. per day to the urinary excretory load. As seen in Figure 2 this increase in urinary solute excretion was accomplished with only a slight increase in urine solute concentration, hence urine volume rose from less than three liters daily during the control to slightly over six liters in one day of the after period. These results indicate that the polyuria, which has become generally accepted as the primary clinical requisite for the diagnosis of neurohypophyseal failure, is dependent upon the quantity of urinary solute and not alone upon the inability to concentrate the urine.

\section{The effects of hormone administration on wa- ter excretion}

Thus far it seemed that the loss of polyuria associated with anterior pituitary insufficiency could be explained without having to consider possible direct diuretic effects of the endocrines. If this subject could be said to have total absence of anterior pituitary function, then the demonstration that the physiological defect of neurohypophyseal insufficiency persisted would be sufficient proof that the anterior pituitary and its subsidiary glands do not produce diuretic hormones which directly affect renal concentrating ability. If the renal concentrating defect of neurohypophyseal insufficiency is unaltered in the absence of anterior pituitary activity then clearly the presence of the latter could not be the cause of this concentrating defect. As clinical methods do not currently afford sufficient sensitivity to establish complete absence of anterior pituitary activity, it was felt that administration of hormones for which direct diuretic effects have been claimed might be of interest. With the subject on a fixed diet affording a constant daily solute load (within the limits of the changes in protoplasmic content that might occur during the study), the only way a hormone could have a direct diuretic action would be to reduce still further the concentrating ability of the subject's kidneys so that a larger urine volume would be required to excrete the fixed excretory load.

Thus thyroxine, $0.75 \mathrm{mgm}$. daily, was given intravenously resulting in an increase in BMR 


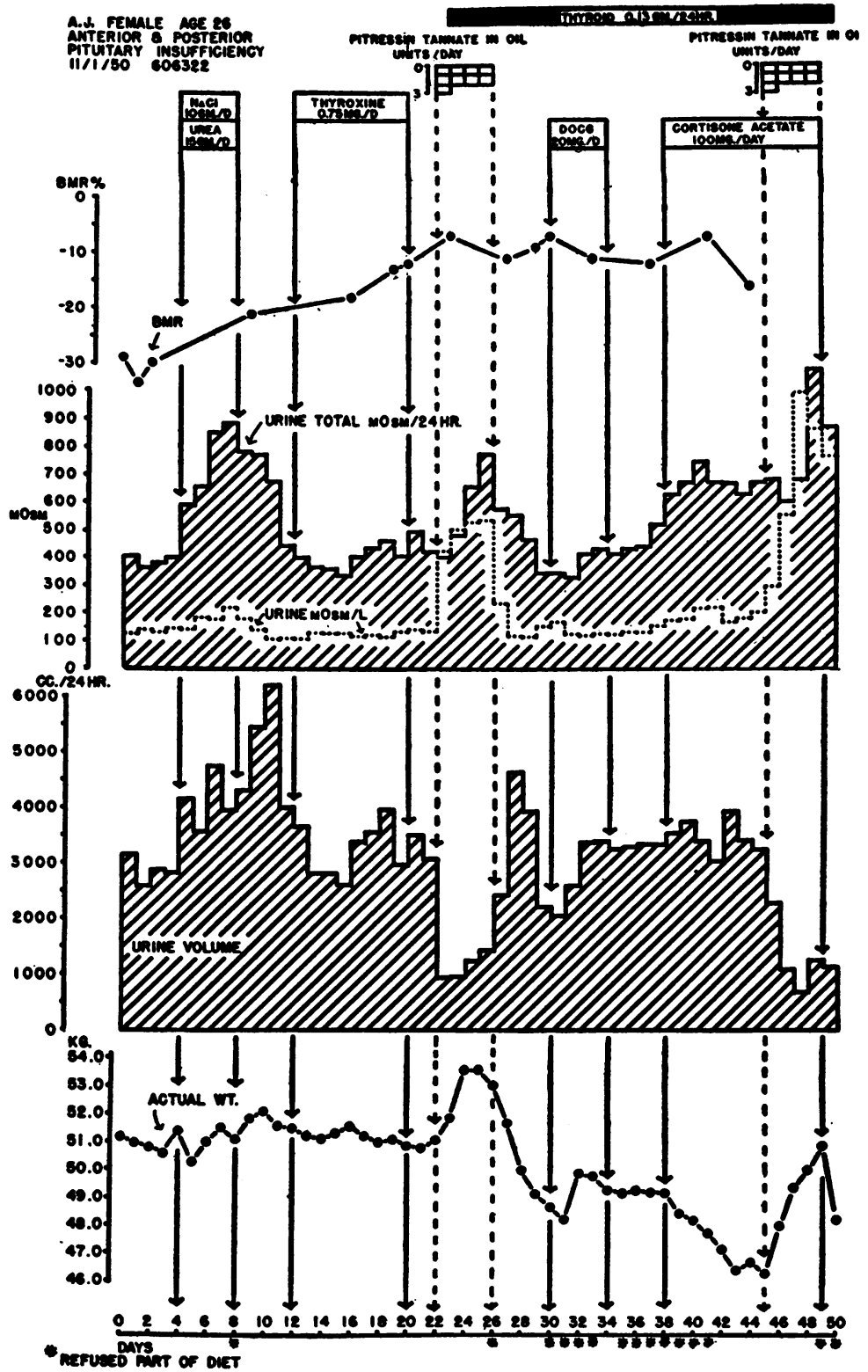

Fig. 2. The Efect of Solute Loading, Intravenous Thyroxine, Pitressin, Desoxycorticosterone Glucoside, Cortisone and Cortisone with Pitressin on BMR, Urine Total Solute Excretion per 24 Hours, Urine Total Solute Concentration, Urine Volume and Body Weight While on a Fixed Diet But an ad lib. Water Intake

Solute loading produced an increase in excretion of solute accomplished with only a slight increase in urine concentration and hence polyuria returned. Thyroxine, desoxycorticosterone and cortisone caused no decrease in urine concentration or increase in urine volume as compared with the control days. Pitressin, both with and without cortisone, resulted in antidiuresis, concentrated urine, weight gain, and an increased total solute excretion reflecting the chloruresis and natriuresis. 
from -30 to -7 per cent with a rise in serum protein-bound iodine concentration from 2.6 to 14 gamma per cent. However there was no further dilution of the urine, and urine volumes remained at the control level (Figure 2). Hence thyroxine could not be demonstrated to have a direct diuretic action in the conditions of this study.

Next pitressin tannate in oil (Parke Davis \& Co., Lot K888j) was administered intramuscularly. Two units were given initially followed by

\section{AJ. FEMALE AGE 26 \\ ANTERIOR \& POSTERIOR \\ PITUITARY INSUFFICIENCY \\ $12 / 31 / 51606322$}

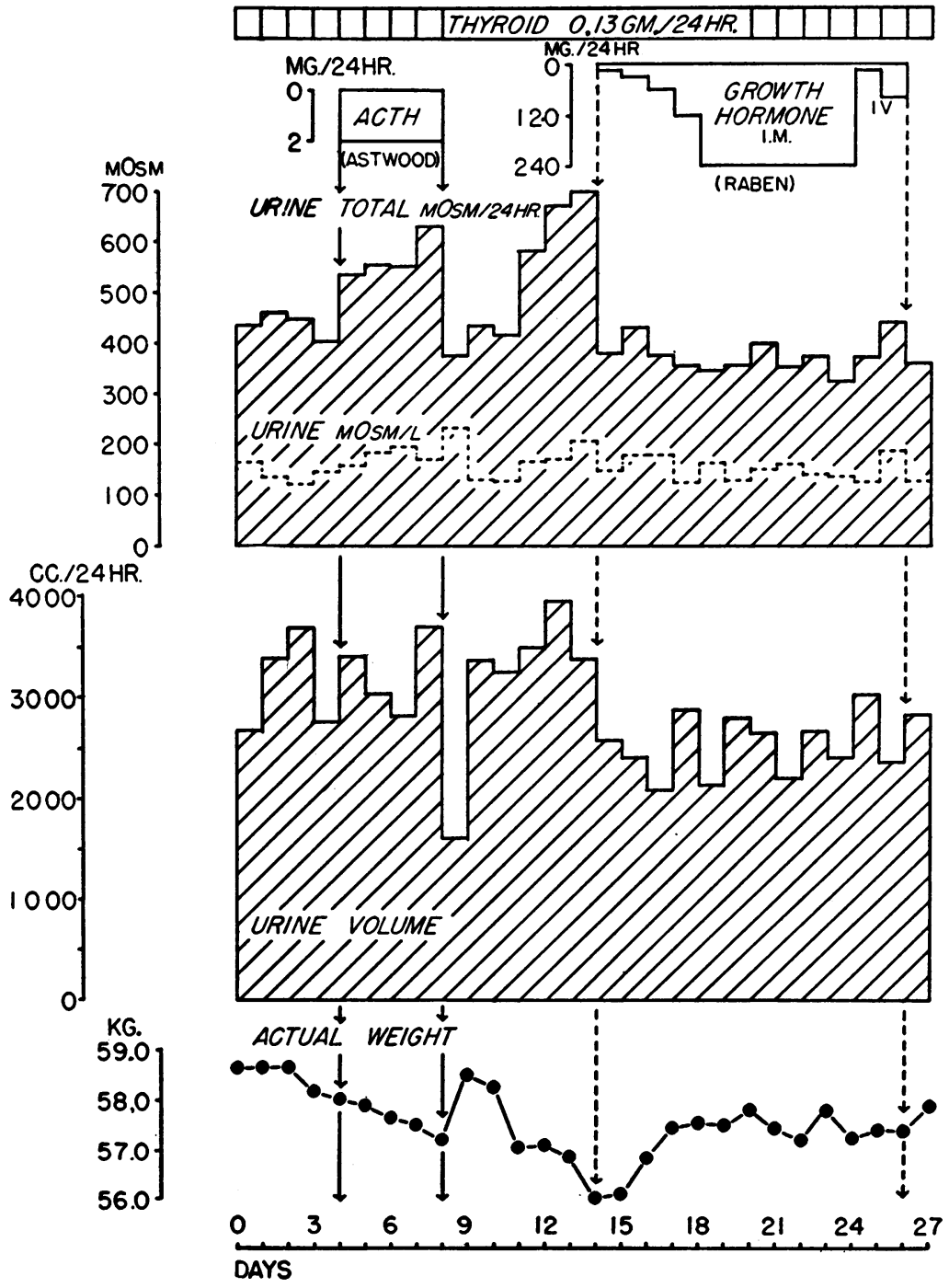

Fig. 3. The Effect of Purified aCth and Growth Hormone on Urine Total Solute Excretion per 24 Hours, Urine Total Solute Concentration, Urine Volume and Body Weight While on a Fixed Diet But an ad Lib. Water Intake

ACTH produced an increase in solute excretion due to an increase in nitrogen excretion (see Figure 8). The second peak in solute excretion resulted from the sodium and chloride diuresis which followed cessation of ACTH administration (see Figure 9). Neither ACTH nor growth hormone effected a dilution of the urine below control concentrations. 


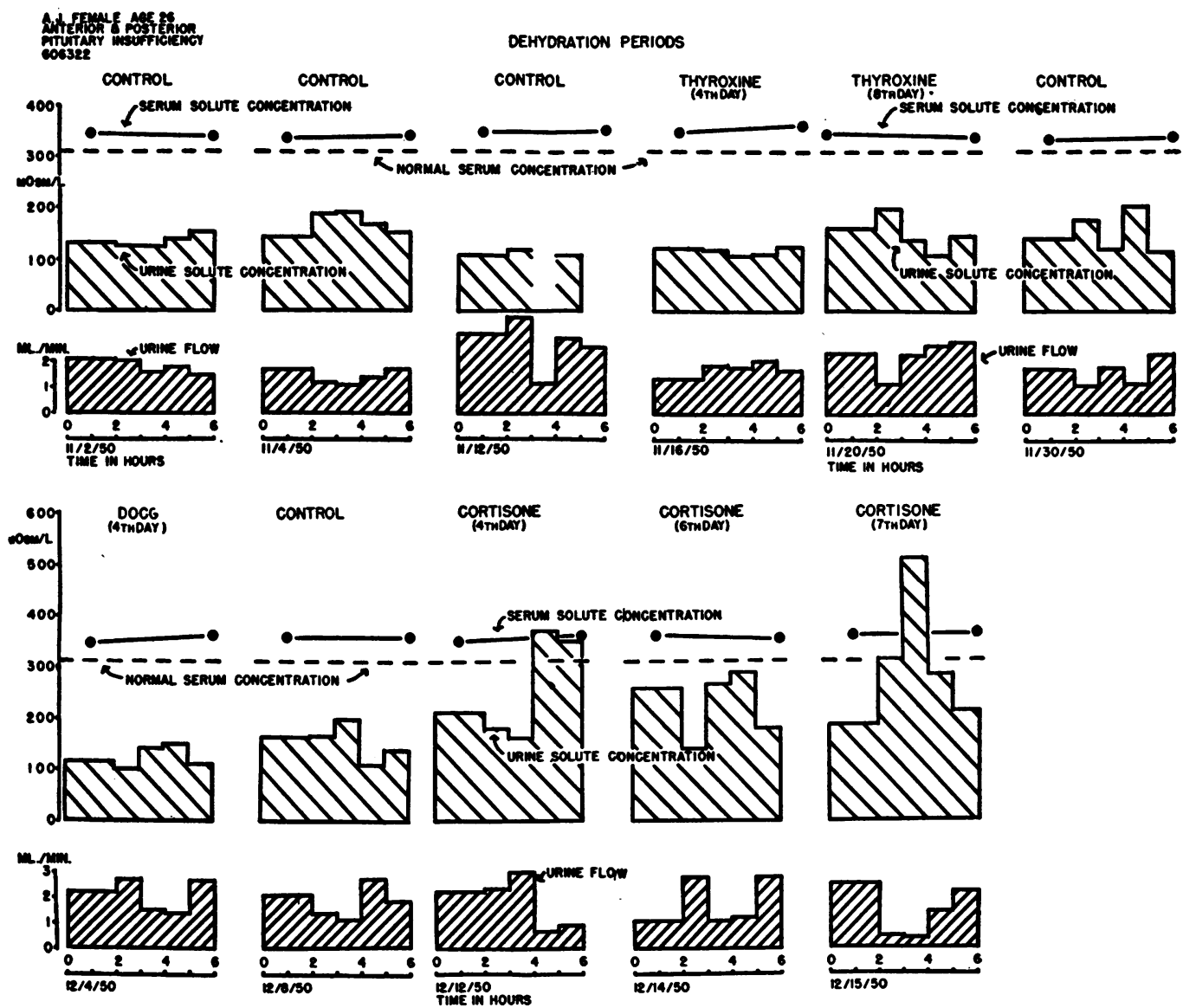

Fig. 4. The Results of a Standard (14-Hour) Water Deprivation on Serum Total Solute Concentration, Urine Total Solute Concentration and Urine Flow

Thyroxine, desoxycorticosterone and cortisone caused no significant lowering of urine concentration or increase in urine flow. Hence they failed to exhibit a diuretic effect under these conditions. " $O$ " on the ordinate was actually the eighth hour of water deprivation.

1 unit every 12 hours for 4 days. The characteristic reduction in urine volume and increase in concentration of the urine with the small amounts of pitressin administered indicates that the subject's kidneys respond normally to antidiuretic hormone (Figure 2).

Desoxycorticosterone glucoside given in four divided dosages totalling $20 \mathrm{mgm}$. daily intramuscularly followed by cortisone acetate $25 \mathrm{mgm}$. four times daily intramuscularly failed also to exhibit diuretic effects; urine concentration did not fall and urine volumes remained at control levels ${ }^{4}$

4 It should be mentioned that anorexia persisted following recovery from the water intoxication produced by pitressin-so that the patient refused part of her diet on several occasions (Figure 2). In spite of some dietary refusals during cortisone, the total solute excretion rose,
(Figure 2). Desiccated thyroid 0.13 gm. daily orally was administered throughout the remainder of the study following cessation of thyroxine injections to preserve a constant normal level of thyroid hormone activity and to exclude the possibility that the other hormones required a normal metabolic rate in order to manifest their diuretic action.

On a subsequent admission, but while receiving the same diet as previously, corticotrophin ${ }^{5}$ (Ast-

due largely to catabolism of body protein with increased nitrogen excretion. This effect of cortisone together with the dietary refusals explains the weight loss during this period (Figure 2).

- We are indebted to Drs. E. B. Astwood and M. S. Raben for generously supplying us with their purified corticotrophin and growth hormone, respectively. 
wood) and growth hormone ${ }^{5}$ (Raben) were administered. Corticotrophin in four divided dosages intramuscularly, totalling $2.0 \mathrm{mgm}$. daily for four days, and growth hormone in divided dosages totalling up to $240 \mathrm{mgm}$. daily intramuscularly and $80 \mathrm{mgm}$. daily intravenously for a total of twelve days likewise failed to exhibit diuretic effects (Figure 3). Renal clearances with inulin and $p$-aminohippurate during this study reveal that the reduced clearances characteristic of pituitary insufficiency (35) which this subject revealed were partially corrected during corticotrophin ad-
TABLE I

Renal clearances

A. J.-surface area $1.50 \mathrm{~m}^{2}$

\begin{tabular}{c|l|c|c|c}
\hline \hline \multicolumn{1}{c|}{ Date } & \multicolumn{1}{|c|}{ Therapy } & Inulin & $\mathrm{PaH}$ & F.F. \\
\cline { 1 - 2 } Mar. 20, 1951 & control & $\begin{array}{c}\text { cc./min. } \\
\text { J5.4 }\end{array}$ & & \\
Jan. 2, 1952 & control & 53.4 & 298 & 0.18 \\
Jan. 7, 1952 & ACTH (day 4) & 75.7 & 336 & 0.23 \\
Jan. 12, 1952 & control & 40.5 & 261 & 0.15 \\
Jan. 19, 1952 & GH* (day 6) & 56.3 & 268 & 0.21 \\
Jan. 22, 1952 & GH (day 9) & 48.7 & 307 & 0.16 \\
Jan. 26, 1952 & GH (day 12) & 51.0 & 293 & 0.17 \\
& & & &
\end{tabular}

Clearances are uncorrected for surface area.

* GH is growth hormone (Raben).

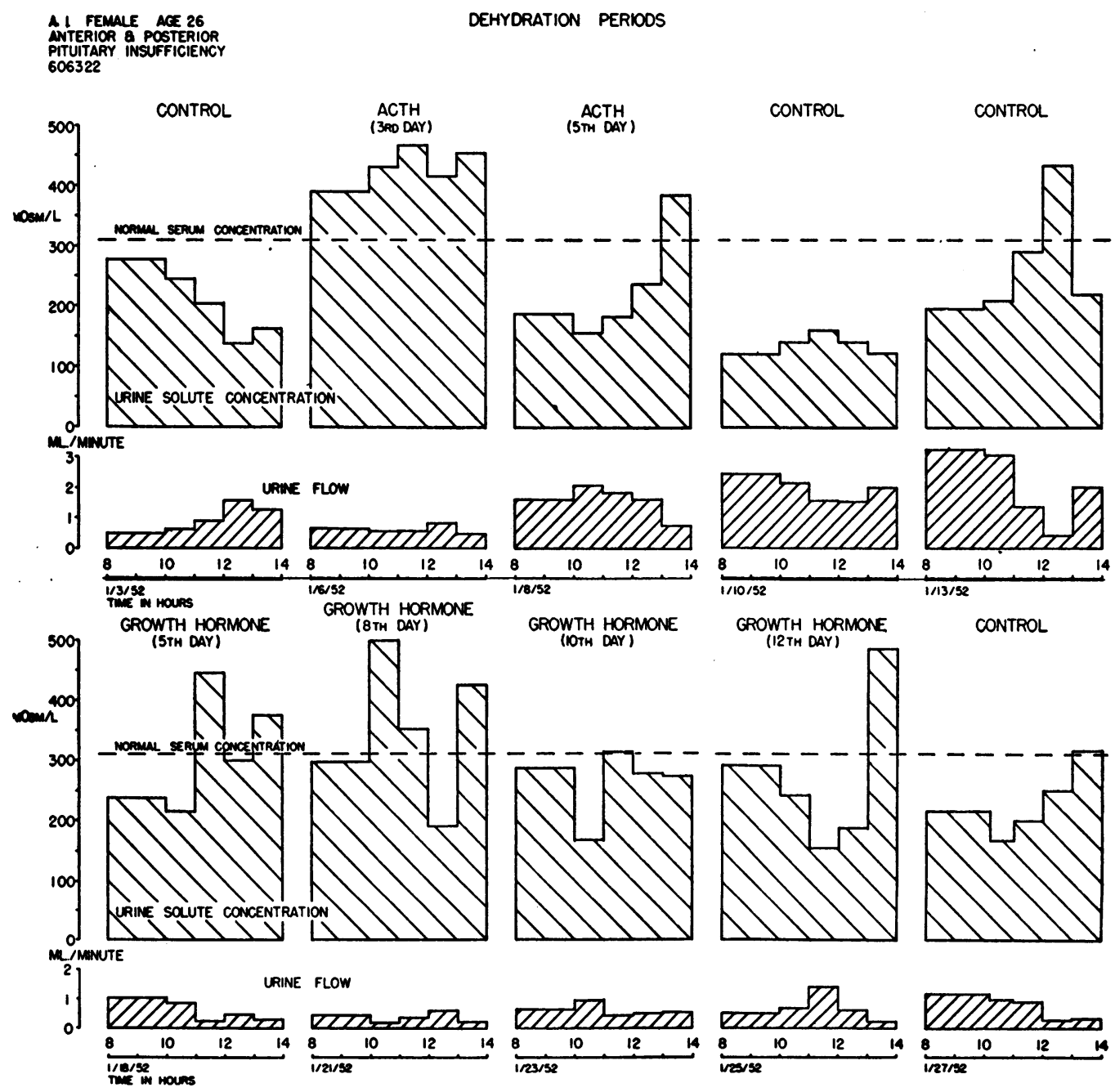

Fig. 5. The Results of the Same Standard Water Deprivation as Described in Fig. 4 Showing the Failure of ACTH and Growth Hormone to Lower Urine Concentration

The hypertonic urines on the third day of ACTH could have been due to slight contamination of the preparation with antidiuretic hormone. This possibility was excluded on the fifth day of ACTH by the duration of the test from the last dosages of ACTH although the eosinophile count at the end of the test was still only 4 per $\mathrm{cmm}$. The sporadic occurrence of urines hypertonic to the serum remains unexplained. 


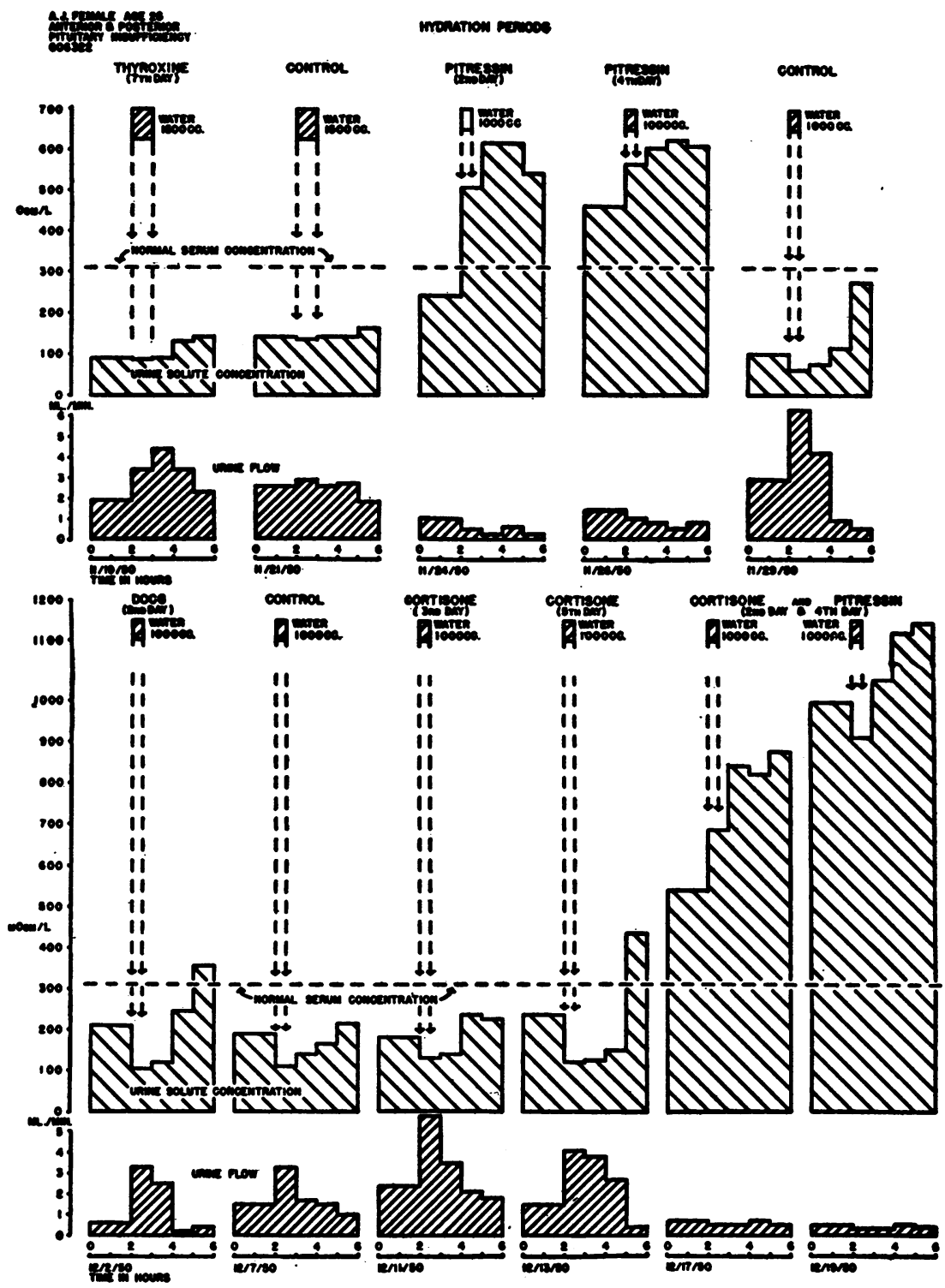

Fig. 6. The Effects of the Various Endocrine Preparations upon the Ability to Hafe a Water Diuresis

Note that with pitressin alone the water diuresis is abolished-urine concentration remains high and urine flow low after water ingestion. Water diuresis occurs during cortisone therapy but with cortisone and pitressin together diuresis is again abolished, and urines of maximal concentration are obtained.

ministration but unaffected by growth hormone (Table I).

To exclude the possibility that variations in fluid intake might be masking any diuretic effects of these hormones in the 24-hour urine collections, the patient was studied in each period under standard conditions of water deprivation. All fluids were withheld after 10:30 p.m. on the preceding night and urine collections were made from 6:30 to $8: 30$ a.m. and then at hourly intervals until 12:30 p.m. Serum was obtained for sodium and total solute concentration at 8:30 a.m. and 12:30 p.m. Breakfast without fluids was allowed. The urine concentrations in Figure 4 show no decrease during thyroxine, desoxycorticosterone or cortisone administration as compared with the control 
periods. The apparent slight improvement in concentrating ability when cortisone was administered remains unexplained but this result is in the opposite direction from a diuretic effect. Figure 5 shows similar results during corticotrophin and growth hormone administration. Hence under the conditions of a nearly fixed excretory solute load no diuretic effect of any of these substances could be detected.

\section{E. Effects of hormone administration on water diuresis}

Figures 6 and 7 show the effect of administration orally of $1000 \mathrm{cc}$. of water on urine flow and urine concentration. It is evident that no significant enhancing effect on water excretion was pro- duced by any of the administered hormones. In addition, Figure 6 shows that the antidiuretic effect resulting from pitressin administration was in no way reduced, but rather augmented when the same small dose of pitressin was administered together with cortisone. This observation suggests that the action of cortisone in correcting the defect of water excretion in Addison's disease is not mediated through an inhibition of antidiuretic hormone effect on the renal tubules.

\section{DISCUSSION}

Present methods for assessing insufficiency of anterior pituitary function are both indirect and insensitive. It is impossible to exclude completely anterior pituitary activity by current methods.

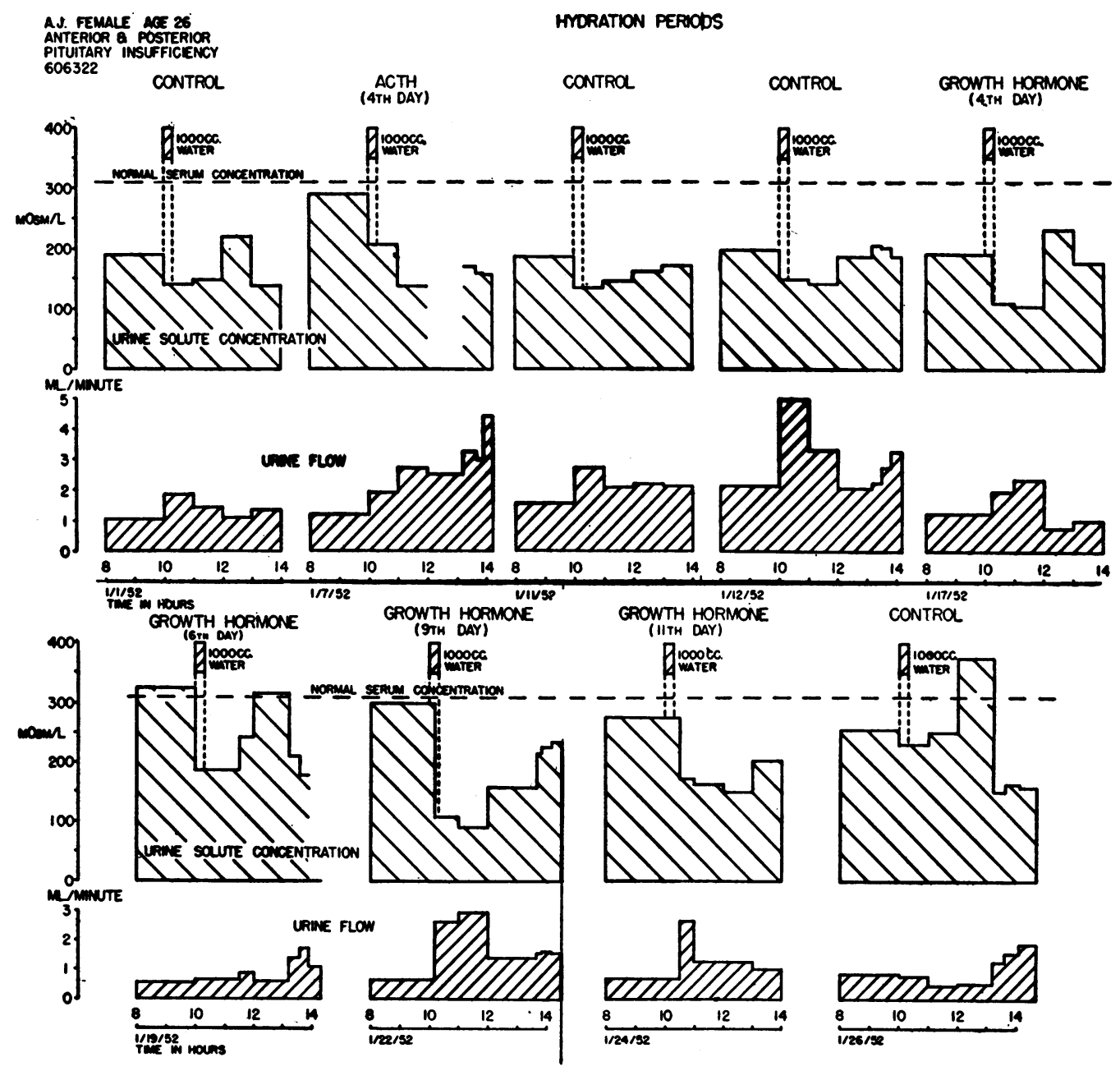

Fig. 7. Similar to Fig. 6 and Shows no Significant Effect of ACTH or Growth Hormone in EnhaNcing a Water DiUresis 


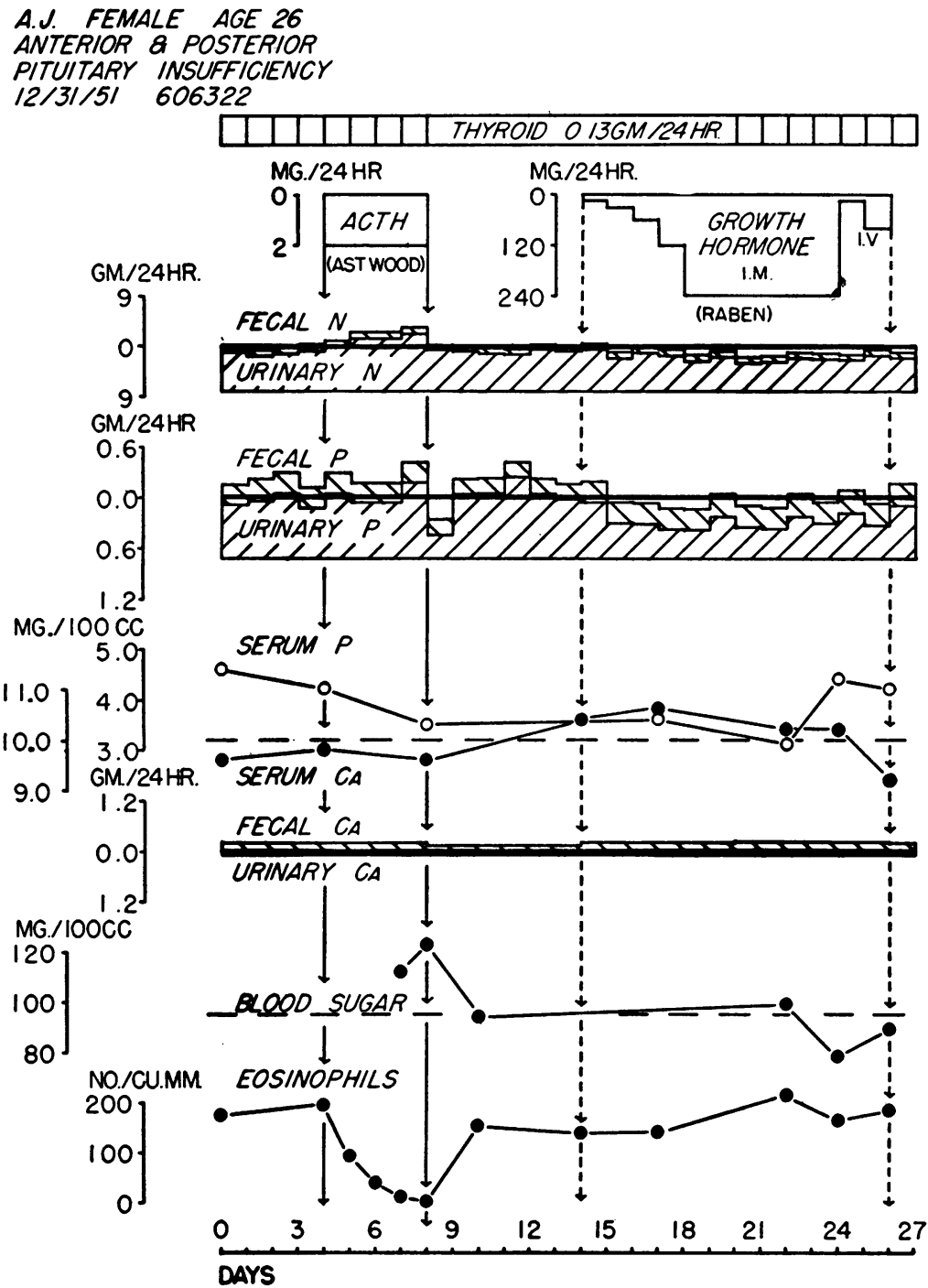

Fig. 8. Metabolic Data on ACTH and Growth Hormone Showing Nitrogen and Phosphorus and Calcium Balances, Serum Phosphorus and Calcium, Blood Sugar and Eosinophiles

Note the retention of nitrogen and phosphorus (indicated by the clear area below the base line) that occurred during growth hormone administration (48). Growth hormone produced no hyperglycemic effect.

For purposes of this study it seemed sufficient that the anterior pituitary failure be associated with spontaneous disappearance of polyuria and polydipsia. In this regard the subject was comparable to the animals experimented on in which the diabetes insipidus state disappeared following destruction of various endocrine glands. The possibility remains, however, that only a slight residual anterior pituitary or adrenal cortical activity is essential to maintain the renal concentrating de- fect of neurohypophyseal failure and that the patient studied had this minimal residual function.

Winter and his associates (36) and Beaser (37) had previously pointed out that polyuria in diabetes insipidus is directly proportional to the excretory load. Richter (38) noted that the food intake of posthypophysectomized rats decreased concomitantly with their fluid exchange following destruction of their anterior pituitary gland. He surmised that diminution of water exchange might 
simply represent the generalized metabolic depression that follows loss of anterior pituitary function. During the period of thyroxine administration, the subject complained of hunger. The increase in appetite which occurs during cortisone or adrenocorticotrophic hormone therapy is now a common clinical observation. It is likely that on a free diet our subject would have had an increased food intake and hence an increased solute excretion with this replacement therapy.

As recently stressed by Crawford, Schoen, and Nicosia (20), availability of solute may constitute a limiting factor in water diuresis. The maximal dilution of urine from normal human kidneys seems to be some 60 to 100 mOsm. per liter. Just as the normal human kidney cannot elaborate a urine during hydropenia above about $1200 \mathrm{mOsm}$. per liter, so also its ability to dilute the urine seems limited. Crawford and associates have shown that the decrease in rate of urine flow in the constantly water-loaded subject is probably the result of a shortage of solute available for excretion. Though the urine remains minimally concentrated, with a decreased rate of total solute excretion the rate of water excretion must also drop off. In our subject, whose urine was always near the lower limits of concentration, the urine volume was of necessity limited by the low rate of solute excretion.

White and Heinbecker have recently reported that growth hormone will re-establish the specific renal clearances in hypophysectomized dogs (39). deBodo and his coworkers reported only a moderate improvement of renal clearances in hypophysectomized dogs given growth hormone (40). In our subject growth hormone (Raben) failed to improve the depressed renal clearances (Table I). This lack of effect of growth hormone on renal clearances is to be contrasted with its anabolic effect in this subject-see phosphorous and nitrogen balances in Figure 8. This observation suggests that growth hormone effect is separable from any renotropic factor of the anterior pituitary.

When corticotrophin was administered there did occur an increase in clearances of about 50 per cent above the control levels in accordance with the findings of Burnett (41). With urines of minimal concentration such as this subject excreted an increase of water reaching the distal tubules as a result of augmented filtration rates could only be excreted if a proportionately greater amount of solute were also available for excretion. A persistent excretion of solute in excess of intake would very soon result in marked deficits of body solute contents. Theoretically it seems inescapable that so long as urines are already minimally concentrated no factors can in-

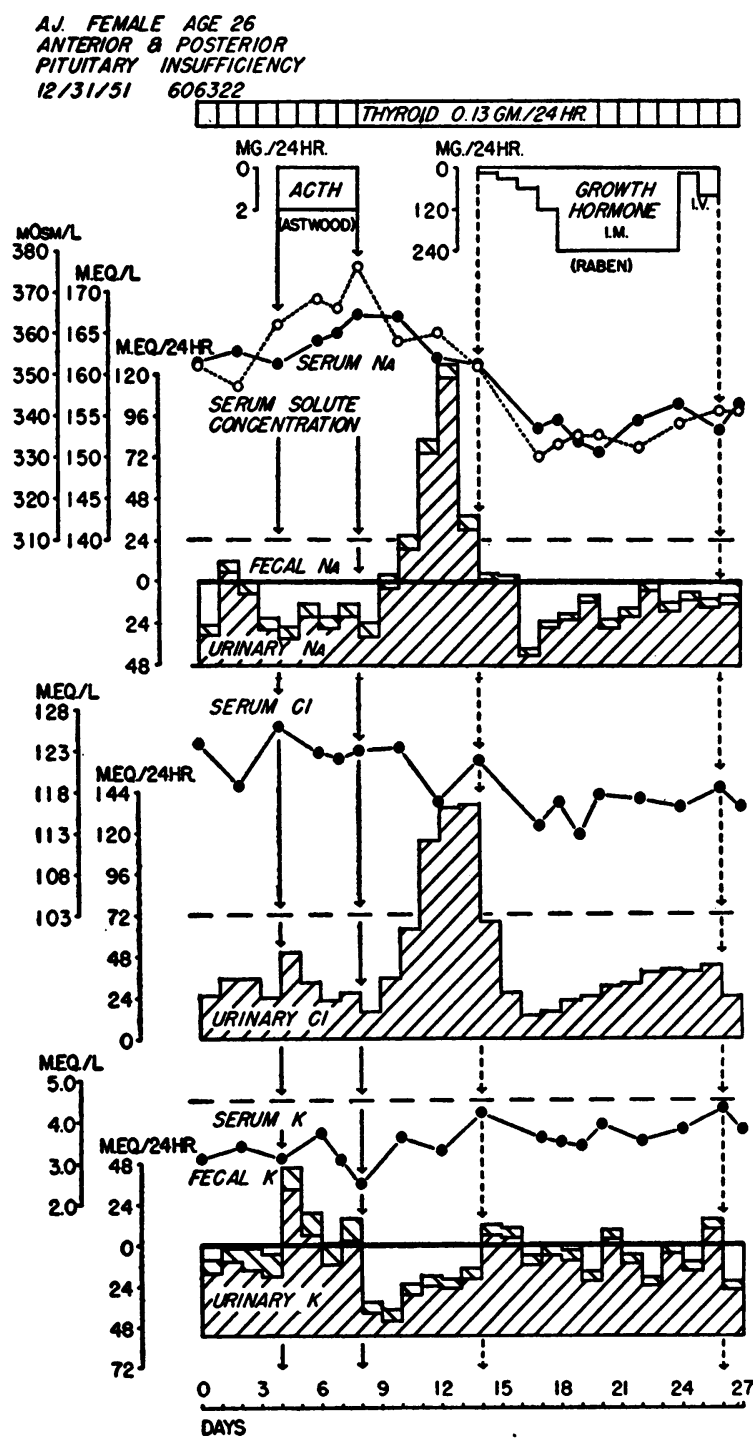

Fig. 9. Metabolic Data on ACTh and Growth Hormone Showing Sodium and Potassium Balances, Urinary Chloride Excretion, and Serum Total Solute, Sodium, Chloride and Potassium Concentrations

Note the abnormally high serum sodium, total solute and chloride concentrations throughout the study (see text). The serum potassium was abnormally low. The control period between ACTH and growth hormone was too brief to permit any interpretation of the sodium and chloride changes that occurred during growth hormone administration. 
crease diuresis which do not, over a prolonged period of time, cause an increase in the intake of solutes which will eventually be excreted through the kidneys. Handley and Keller have appropriately suggested that the decrease in renal clearances subsequent to hypophysectomy serves as a defensive mechanism preventing depletion of body constituents (42).

- It was somewhat of a surprise to find the subject excreting only minute amounts of sodium in the urine during the initial control period and following the pitressin period in spite of a daily sodium intake of $50 \mathrm{mEq}$. and an elevated serum sodium concentration. Such a degree of renal conservation of sodium probably indicates some residual adrenal cortical activity (43) and has been reported in totally hypophysectomized dogs (44). This pattern of a high serum sodium concentration with only small amounts of sodium in the urine is similar to that of the "dehydration reaction" characteristic of simple water restriction $(45,46)$. During the solute loading period, serum sodium, chloride, and total solute concentrations rose to alarming levels and drowsiness, apathy and anorexia on the fourth day caused refusal of part of the diet and sodium chloride-urea mixture. The failure of the patient to ingest sufficient water while on an ad libitum water intake to correct this hypertonicity of her serum suggests that her "thirst center," as well as her pituitary, was damaged.

That the hormones tested had no direct renal effect on water excretion in this subject with neurohypophyseal failure, obviously does not exclude the possibility that with some residual neurohypophyseal function these hormones might be effective through inhibiting the release of antidiuretic hormone or interfering with the action of antidiuretic hormone on the renal tubule. The latter possibility has been excluded in the present study only in the case of cortisone. That the subject with Addison's disease during treatment with cortisone can elaborate urines of maximal concentration during water deprivation (47) indicates that cortisone does not interfere with the normal release of antidiuretic hormone.

\section{SUMMARY AND CONCLUSIONS}

1. A patient with diabetes insipidus due to known neurohypophyseal insufficiency who sub- sequently developed evidence of some anterior pituitary failure is presented.

2. Spontaneous disappearance of polyuria and polydipsia occurred concomitantly with dysfunction of the anterior pituitary thus simulating the situation in the animal with experimental diabetes insipidus whose water exchange returns toward normal following ablation of the anterior pituitary.

3. In spite of the disappearance of polyuria the physiological defect which characterizes neurohypophyseal insufficiency persisted. This defect is an inability to elaborate a concentrated urine in response to the stimulus of an elevated effective total solute concentration of the serum.

4. The disappearance of polyuria could be satisfactorily explained in this case as resulting from a decrease in the excretory solute load. When the excretory solute load was increased, polyuria recurred.

5. When the excretory solute load was kept nearly fixed by adherence to a constant diet, the administration of thyroxine, desoxycorticosterone glucoside, cortisone, corticotrophin, and growth hormone could not be shown to have any effect on water excretion. The urine concentration did not fall and volume did not increase.

6. It is suggested that any diuretic effects previously noted for these substances were secondary to their general effects of increasing metabolism, activity, food intake, and hence the excretory solute load. The possibility that they may interfere with the release or action of antidiuretic hormone also exists.

7. Cortisone administration in no way diminished the antidiuretic effect of pitressin injections.

\section{ACKNOWLEDGMENT}

The authors wish to express their gratitude to Drs. James H. Means and Walter Bauer whose interest and support made possible this study. Their thanks go also to Dr. Fuller Albright, whose patient was the subject for this study, and to Dr. J. D. Crawford, who generously made available his freezing point depression apparatus.

\section{REFERENCES}

1. v. Hann, F., Uber die Bedeutung der Hypophysenveranderungen bei Diabetes insipidus. Frankfurt. Ztschr. Path., 1918, 21, 337.

2. Richter, C. P., The pituitary gland in relation to water exchange, in The Pituitary Gland. Williams and Wilkins Co., Baltimore, 1938. 
3. Pencharz, R. I., Hopper, J., Jr., and Rynearson, E. H., Water metabolism in the rat following removal of the anterior lobe of the hypophysis. Proc. Soc. Exper. Biol. \& Med., 1936, 34, 14.

4. Schweizer, M., Gaunt, R., Zinken, N., and Nelson, $\mathrm{W}$. O., The rôle of the adrenal cortex and the anterior pituitary in diabetes insipidus. Am. J. Physiol., 1941, 132, 141.

5. Richter, C. P., Experimental diabetes insipidus: its relation to the anterior and posterior lobes of the hypophysis. Am. J. Physiol., 1934-35, 110, 439.

6. White, H. L., and Heinbecker, P., Pituitary regulation of water exchange in the dog and monkey. Am. J. Physiol., 1937, 118, 276.

7. Biggart, J. H., and Alexander, G. L., Experimental diabetes insipidus. J. Path. \& Bact., 1939, 48, 405.

8. Mahoney, W., and Sheehan, D., The effect of total thyroidectomy upon experimental diabetes insipidus in dogs. Am. J. Physiol., 1935, 112, 250.

9. Fisher, C., Ingram, W. R., and Ranson, S. W., Diabetes insipidus and the neuro-hormonal control of water balance: a contribution to the structure and function of the hypothalamico-hypophyseal system. Edward Brothers, Inc., Ann Arbor, Michigan., 1938.

10. Bruhn, J. M., The relation of heat production to water metabolism during the administration of synthetic thyroxine. Am. J. Physiol., 1941-42, 135, 572.

11. Blotner, H., and Cutler, E. C., Total thyroidectomy in the treatment of diabetes insipidus. J. A. M. A., 1941, 116, 2739.

12. Radcliffe, C. E., Observations on the relationship of the thyroid to the polyuria of experimental diabetes insipidus. Endocrinology, 1943, 32, 415.

13. Keller, A. D., Hypophyseal thyrotropic mechanism essential for occurrence of diabetes insipidus in its maximal form. Proc. Soc. Exper. Biol. \& Med., 1937, 36, 787.

14. Ingram, W. R., and Fisher, C., Effects of thyroidectomy, castration, anterior lobe administration and pregnancy upon experimental diabetes insipidus in the cat. Endocrinology, 1937, 21, 273.

15. Silvette, H., and Britton, S. W., Renal function in the opossum and the mechanism of cortico-adrenal and post-pituitary action. Am. J. Physiol., 1938, $123,630$.

16. Gaunt, R., Birnie, J. H., and Eversole, W. J., Adrenal cortex and water metabolism. Physiol. Rev., 1949, 29, 281.

17. Gaunt, R., and Birnie, J. H., Hormones and Body Water. American Lecture Series No. 103, American Lectures in Physiology. Charles C. Thomas, Springfield, III., 1951.

18. Reifenstein, E. C., Jr., Albright, F., and Wells, S. L., The accumulation, interpretation, and presentation of data pertaining to metabolic balances, notably those of calcium, phosphorous, and nitrogen. J. Clin. Endocrinol., 1945, 5, 367.
19. Butler, A. M., and Tuthill, E., An application of the uranyl zinc acetate method for determination of sodium in biological material. J. Biol. Chem., 1931, 93, 171.

20. Crawford, J. D., Schoen, E. J., and Nicosia, A. P., Factors determining maximum renal water excretion capacity. Proc. Soc. for Ped. Research, May, 1951. Am. J. Dis. Child., 1952, 83, 91. 91.

21. Berry, J. W., Chappell, D. G., and Barnes, R. B., Improved method of flame photometry. Indust. \& Engin. Chem., Analytical Edition, 1946, 18, 19.

22. Wilson, D. W., and Ball, E. G., Study of estimation of chloride in blood and serum. J. Biol. Chem., 1928, 79, 221.

23. Van Slyke, D. D., and Neill, J. M., The determination of gases in blood and other solutions by vacuum extraction and manometric measurement. I. J. Biol. Chem., 1924, 61, 523.

24. Folin, O., and $\mathrm{Wu}, \mathrm{H}$., A system of blood analysis. J. Biol. Chem., 1919, 38, 81.

25. Roth, P., Modifications of apparatus and improved technic adaptable to the Benedict type of respiration apparatus. Boston M. \& S. J., 1922, 186, 457 and 491.

26. Goldring, W., and Chasis, H., Hypertension and $\mathrm{Hy}$ pertensive Disease. The Commonwealth Fund, New York, 1944.

27. Klinefelter, H. F., Jr., Albright, F., and Griswold, G. C., Experience with a quantitative test for normal or decreased amounts of follicle stimulating hormone in the urine in endocrinological diagnosis. J. Clin. Endocrinol., 1943, 3, 529.

28. Carter, A. C., and Robbins, J., The use of hypertonic saline infusions in the differential diagnosis of diabetes insipidus and psychogenic polydipsia. $\mathrm{J}$. Clin. Endocrinol., 1947, 7, 753.

29. Fraser, R. W., Forbes, A. P., Albright, F., Sulkowitch, H., and Reifenstein, E. C., Jr., Colorimetric assay of 17 -ketosteroid in urine. A survey of the use of this test in endocrine investigation, diagnosis, and therapy. J. Clin. Endocrinol., 1941, $1,234$.

30. Ham, T. H., A syllabus of laboratory examinations in clinical diagnosis. Harvard University Press, Cambridge, Mass., 1950, page 408.

31. Barker, S. B., Determination of protein-bound iodine. J. Biol. Chem., 1948, 173, 715.

32. Fraser, R. W., Albright, F., and Smith, P. H., The value of the glucose tolerance test, the insulin tolerance test, and the glucose-insulin tolerance test in the diagnosis of endocrinologic disorders of glucose metabolism. J. Clin. Endocrinol., 1941, 1, 297.

33. Leaf, A., and Mamby, A. R., The normal antidiuretic mechanism in man and dog; its regulation by extracellular fluid tonicity. J. Clin. Invest., 1952, 31, 54.

34. Verney, E. B., Antidiuretic hormone and the factors which determine its release. Proc. Roy. Soc. London, s. B, 1947-48, 135, 25. 
35. White, H. L., and Heinbecker, P., Observations on inulin and diodrast clearances and on renal plasma flow in normal and hypophysectomized dogs. Am. J. Physiol., 1940, 130, 464.

36. Winter, C. A., Ingram, W. R., and Eaton, R. C., Effect of dietary changes upon urine volume and renal function in experimental diabetes insipidus. Am. J. Physiol., 1943, 139, 700.

37. Beaser, S. B., Renal excretory function and diet in diabetes insipidus. Am. J. M. Sc., 1947, n.s. 213, 441.

38. Richter, C. P., Experimental diabetes insipidus: its its relation to the anterior and posterior lobes of the hypophysis. Am. J. Physiol., 1934-35, 110, 439.

39. White, H. L., Heinbecker, P., and Rolf, D., Renotropic effects of growth hormone preparations. Am. J. Physiol., 1951, 165, 442.

40. de Bodo, R. C., Schwartz, I. L., Greenberg, J., Kurtz, M., Earle, D. P., Jr., and Farber, S. J., Effect of growth hormone on water metabolism in hypophysectomized dogs. Proc. Soc. Exper. Biol. \& Med., 1951, 76, 612.

41. Burnett, C. H., The actions of ACTH and cortisone on renal function in man. Renal Function. Transactions of the Second Conference, October 19-20,
1950. Josiah Macy, Jr. Foundation, New York, 1951, page 106.

42. Handley, C. A., and Keller, A. D., Changes in renal functions associated with diabetes insipidus precipitated by anterior hypothalamic lesions. Am. J. Physiol., 1950, 160, 321.

43. Leaf, A., and Couter, W. T., Evidence that renal sodium excretion by normal human subjects is regulated by adrenal cortical activity. J. Clin. Invest., 1949, 28, 1067.

44. Earle, D. P., Jr., de Bodo, R. C., Schwartz, I. L., Farber, S. J., Kurtz, M., and Greenberg, J., Effect of hypophysectomy on electrolyte and water metabolism in the dog. Proc. Soc. Exper. Biol. \& Med., 1951, 76, 608.

45. Elkinton, J. R., and Taffel, M., Prolonged water deprivation in the dog. J. Clin. Invest., 1942, 21, 787.

46. Peters, J. P., Sodium, water and edema. J. Mt. Sinai Hosp., 1950-51, 17, 159.

47. Leaf, A., and Mamby, A. R., An antidiuretic mechanism not regulated by extracellular fluid tonicity. J. Clin. Invest., 1952, 31, 60.

48. Raben, M. S., Westermeyer, V. W., and Leaf, A., Metabolic effects of a new growth hormone preparation. Proc. 44th Annual Meeting, Am. Soc. Clin. Invest. J. Clin. Invest., 1952, 31, 655. 